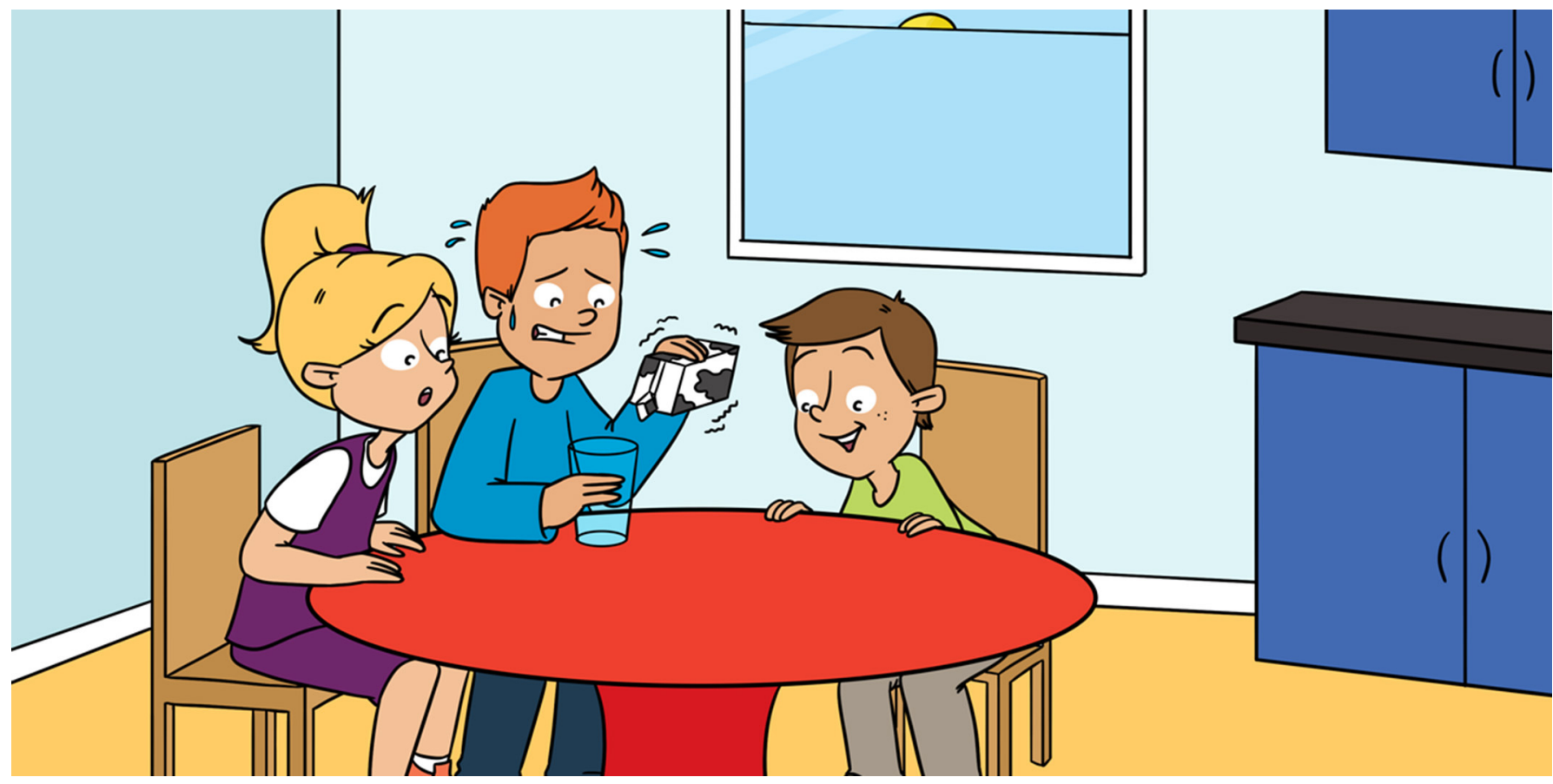

\title{
WHY DO WE "CHOKE" UNDER PRESSURE?
}

\section{Stefania A. Ciurea, Ashleigh M. Maxcey * and Phillip M. Newman}

Department of Psychology, Vanderbilt University, Nashville, TN, United States

YOUNG REVIEWERS:

EXPLORA

SCIENCE

CENTER

AND

CHILDREN'S

MUSEUM

AGES: 8-14
Why do some people perform worse under pressure, even when using a familiar skill to complete a task? This is called choking under pressure, and it happens to many people and in many different situations. Understanding when and why people choke under pressure can help us perform at our best when it matters the most. In this article, we explain the scientific research on the parts of the brain that cause choking under pressure and how we can prevent this impaired performance from happening.

\section{WHAT DOES IT MEAN TO "CHOKE" UNDER PRESSURE?}

Imagine that you are sitting in class taking a test. You studied really hard, but you suddenly forget an important piece of information that you need to solve a problem. As you try your hardest to remember that one fact, you panic. Your heart races, you start to sweat, and you cannot seem to think clearly anymore. This feeling of panic, often called choking under pressure, is a response of the nervous system to really stressful situations, and it can cause people to perform badly on a task (Figure 1) [1, 2]. Not to be confused with difficulty breathing, "choking" under pressure happens when feelings of stress, worry, and 
Figure 1

Ways in which our bodies respond to choking under pressure. There are many ways your body can react in high pressure situations like when taking a test. For example, you might feel your hands start shaking or your palms get sweaty. These types of reactions are different from person to person and can affect how well you do on the test.

\section{WORIING MEMORY}

A limited storage space for memories that we are currently thinking about or using.

\section{LONG-TERM MEMORY}

An unlimited storage of memories that we are not currently using.

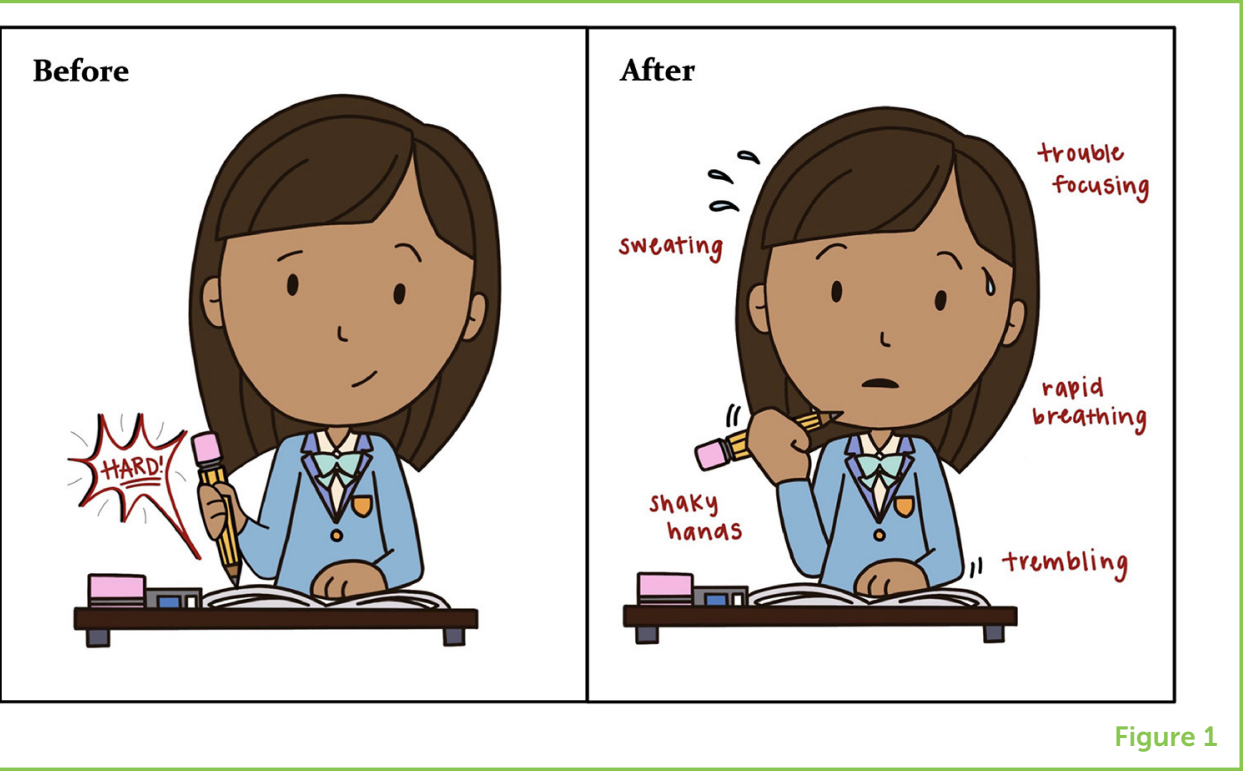

anxiety work together to cause someone to perform worse than they normally would. In the example above, the test can either give you a great reward (getting an $\mathrm{A}+$ ) or a punishment (getting a bad grade). This kind of stressful, risky situation can play a big role in how much information a student can remember in the moment.

While the idea of choking under pressure might seem pretty straightforward, the science behind it is complicated. For example, scientists think that choking under pressure involves memory-specifically, a type of memory called working memory [3]. Not only does choking involve working memory, but it also depends on how different parts of the brain communicate with each other $[2,4]$.

In this article, we describe the scientific discoveries that help us understand how brain activity comes together to cause choking under pressure. We focus on how choking affects students, but remember that choking under pressure can affect a variety of people and can happen in many different situations, like in sports or competitions. Because choking under pressure happens so often and to so many people, it is important to understand how it works so that we can try to stop it from happening.

\section{THE ROLE OF WORKING MEMORY}

Scientists who study memory have described different processes, or types, of memory [3]. One type is called long-term memory, which lasts basically forever and can store an unlimited amount of information. Long-term memory stores the information we are not currently using, kind of like a library full of books that hold the stories of our lives. Another type of memory, working memory, does not 
INDIVIDUAL

WORKING MEMORY CAPACITY

The amount of information (or capacity) people can hold in working memory differs slightly across people, meaning that each individual (or person) has their own working memory capacity. last very long and cannot hold much information. Working memory is the one we use for completing tasks and getting information into and out of long-term memory. For example, we use working memory to do things like mental math or to piece a story together after listening to a sequence of events. Working memory plays a big role in learning and doing well on tests in school [3]. People differ in how much information they can hold in working memory, which is called a person's individual working memory capacity.

Stressful situations can affect even the smartest students, by lowering the amount of space in their working memory [1, 2, 4]. Remember that working memory already cannot hold much information. When students are placed in high-pressure situations (like on a test day), worrying about the pressure they are under takes up space in working memory and leaves less space available to use to complete the task. For example, when taking a test, anxious thoughts use up some of the limited space in working memory and lower the amount of working memory space available for solving a math problem or pulling a fact out of long-term memory.

\section{HOW DO WE KNOW THIS?}

Scientists created an experiment to look at how low- or high-pressure situations affected students with different individual working memory capacities. First, the scientists measured the working memory capacities of 93 students. They did this by giving the students two tests: one that involved solving math problems while remembering a list of random words and one in which students were told to read sentences aloud while remembering random letters. Based on their performance on these tests, the students were placed into two groups: students with high-capacity working memory (these students can hold more information in working memory and are represented in blue on Figure 2) and students with low-capacity working memory (represented in red in Figure 2).

Then, the scientists gave each group a set of math problems in two situations: a low-pressure and a high-pressure situation. They did this to figure out if more space in working memory meant students had enough room to store both the math problem and the stress/high-pressure thoughts, and whether this affected how well they could do on the math problems. To create the high-pressure environment, the scientists gave the students real-world sources of stress, like the possibility of winning money based on how quickly and correctly they could do the math problems. The low-pressure situation was described to the students as practice.

The results of this experiment (Figure 2) showed that students with higher working memory perform better than students with lower working memory under low-pressure conditions. This means that, 
Figure 2

Results of the working memory experiment.

The high-capacity working memory students (blue) performed better than low-capacity working memory students (red) under low pressure. However, when the stakes were high, the high-capacity working memory students performed equally to the low-capacity working memory students!
PREFRONTAL

\section{CORTEX}

A part of the brain located in the frontal lobe that is involved in complex behaviors.

\section{COGNITIVE}

Relating to the process of thinking.
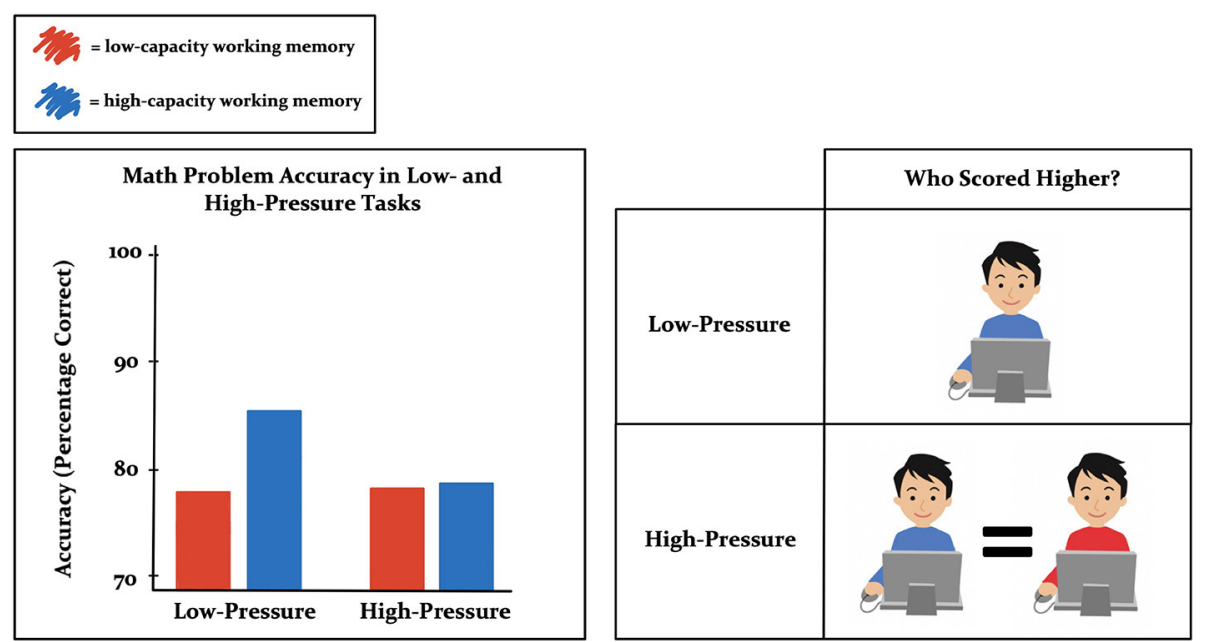

Figure 2

when there is no pressure, the high-capacity students can do better on math tests. This makes sense, because these students have more working memory space to conduct mental math or to retrieve information from long-term memory. However, when the pressure was on, the high working memory students performed equally to the students with low working memory! This means that, under pressure, anxious and stressful thoughts consumed the extra working memory capacity of the high-capacity students, and they were not able to use their higher working memory capacity to outperform the students with low working memory capacity. This result might also explain why the students with low-capacity working memory did not do any worse in the high-pressure situation than in the low-pressure situation: they had no available working memory space leftover to process and store the idea that they were under pressure! This research not only shows how important working memory is in the school setting, but also how stressful situations can stop people from doing as well as they potentially can when it matters the most.

\section{PARTS OF THE BRAIN INVOLVED IN CHOKING}

Can we point to one part of the brain and say, "that is where choking under pressure happens?" For a long time, scientists thought that the prefrontal cortex, which is really important for a lot of cognitive functions like planning, reasoning, and decision-making, was responsible for holding information in working memory [1, 4]. These scientists came to this conclusion because they noticed high levels of brain activity in the prefrontal cortex when humans used their working memories [5]. Recent studies show that cognitive functions, like attention and motivation, play a key role in determining how much working memory capacity person can have. For example, the more attention a person's prefrontal cortex can give to a task, the more working memory that person has. Basically, the prefrontal cortex picks 
ANTERIOR

CINGULATE CORTEX

A part of the brain that is involved in impulse control, emotion, and decision-making.

\section{AMYGDALA}

An almond-shaped area of the brain that is involved in in emotion and behavior.

\section{MESO-LIMBIC-}

\section{CORTICAL}

\section{PATHWAY}

A reward pathway in the brain that plays a role in processing reward information.

and chooses the important information to attend to, and processes that information in a way that affects working memory capacity. So, we know that there is a connection between the prefrontal cortex and working memory. But, there is more!

Another part of the brain, called the anterior cingulate cortex, is involved in controlling our emotions [4]. In the testing example described above, this emotional center of the brain would have played a role in causing the moment of panic when you realized you forgot something on the test. Together with the anterior cingulate cortex, the amygdala also plays a role in how we perceive fear and anxiety. The amygdala is a small, almond-shaped part of the brain that plays a role in how we respond when we are under pressure [6]. This means that the prefrontal cortex alone is not responsible for choking under pressure. So, we know that the prefrontal cortex helps guide attention and the anterior cingulate cortex and amygdala help control our emotions. But this still is not the whole story, because taking a test does not just involve attention and emotion, performing well on a test involves motivation too.

There is a highway in the brain called the meso-limbic-cortical pathway that plays a role in how rewarding a situation feels to us [4]. This part of the brain would be partly responsible for the pressure we feel to get an A+ on tests-because we want the reward of doing well in school and we see the risk in doing poorly on the test.

Let us return to the question above, can we point to one part of the brain and say that is where choking under pressure happens? The answer is no. Many tasks the brain accomplishes are spread across many areas of the brain, meaning we cannot just point to one part of the brain and say, "that is where choking under pressure happens." But we can describe how several regions of the brain are involved, including the prefrontal cortex, anterior cingulate cortex, amygdala, and the meso-limbic-cortical pathway (Figure 3).

\section{HOW CAN WE AVOID CHOKING UNDER PRESSURE?}

Luckily, there are some steps we can take to prevent choking under pressure. Recent studies have shown that writing about your thoughts before taking a test is very helpful in preventing choking, probably because it frees up the working memory space that any negative or overwhelming thoughts were using, by getting those thoughts down on paper instead. Also, practicing under pressure (like studying in a way that is similar to the actual test) gives you a chance to practice pausing and breathing during hard problems [1]. 
Figure 3

Parts of the brain involved in choking under pressure. The meso-limbic-cortical pathway, which controls how we perceive reward, is shown in red; it starts in a part of the brain called the ventral tegmental area and moves up through the prefrontal cortex. The anterior cingulate cortex, which is involved in controlling our emotions, is shown by the dashed white line. The amygdala, which also plays a role in how we perceive fear and anxiety, is also pictured.

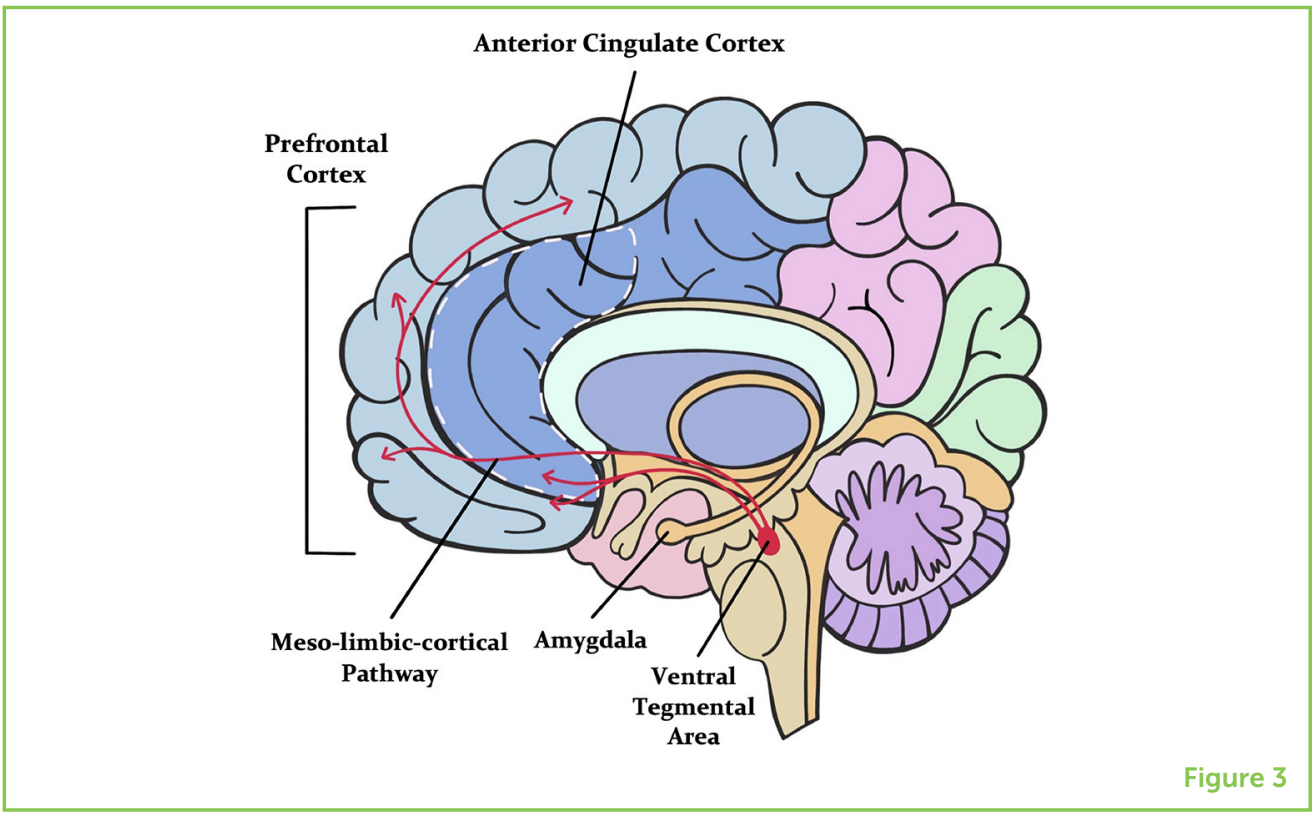

\section{SUMMARY}

At some point in our lives, most of us will experience a moment when we choke under pressure. Our stressful emotional state may cause us to seemingly forget an important piece of information, and this can result in worse performance on the task than we expected. Scientists have shown that choking under pressure interrupts the functioning of working memory. If you interrupt the ability of working memory to stay focused on a task, performance can suffer because of changes to attention that occur in the prefrontal cortex, emotions that occur in the anterior cingulate cortex and amygdala, and motivation that happens in the meso-limbic-cortical pathway. Luckily, practicing staying calm and jotting your feelings down on paper to get them out of your working memory are strategies that can reduce choking under pressure.

Although we know which brain areas are involved in choking under pressure, more research is needed to learn how the mechanisms and pathways in these areas interact with each other, so we can understand how to perform at our best when there is a lot on the line.

\section{REFERENCES}

1. Beilock, S. 2010. Choke: What the Secrets of the Brain Reveal About Getting It Right When You Have To. 1st Edn. New York, NY: Atria Paperback.

2. Beilock, S. L., and Carr, T. H. 2005. When high-powered people fail: working memory and "choking under pressure" in math. Psychol. Sci. 16:101-5. doi: 10.1111/j.09567976.2005.00789

3. Cowan, N. 2014. Working memory underpins cognitive development, learning, and education. Educ. Psychol. Rev. 26:197-223.

doi: 10.1007/s10648-013-9246-y 
4. Yu, R. 2015. Choking under pressure: the neuropsychological mechanisms of incentive induced performance decrements. Front. Behav. 9:19.

doi: $10.3389 /$ fnbeh.2015.00019

5. Curtis, C. E., and D'Esposito, M. 2003. Persistent activity in the prefrontal cortex during working memory. Trends Cogn. Sci. 7:415-23.

doi: 10.1016/S1364-6613(03)00197-9

6. Ressler, K. J. 2010. Amygdala activity, fear, and anxiety: modulation by stress. Biol. Psychiatry 67:1117-9. doi: 10.1016/j.biopsych.2010.04.027

SUBMITTED: 27 December 2019; ACCEPTED: 27 March 2020; PUBLISHED ONLINE: 13 May 2020.

EDITED BY: Kathleen Y. Haaland, University of New Mexico, United States

CITATION: Ciurea SA, Maxcey AM and Newman PM (2020) Why Do We "Choke" Under Pressure? Front. Young Minds 8:56. doi: 10.3389/frym.2020.00056

CONFLICT OF INTEREST: The authors declare that the research was conducted in the absence of any commercial or financial relationships that could be construed as a potential conflict of interest.

COPYRIGHT @ 2020 Ciurea, Maxcey and Newman. This is an open-access article distributed under the terms of the Creative Commons Attribution License (CC BY). The use, distribution or reproduction in other forums is permitted, provided the original author(s) and the copyright owner(s) are credited and that the original publication in this journal is cited, in accordance with accepted academic practice. No use, distribution or reproduction is permitted which does not comply with these terms.

\section{YOUNG REVIEWERS}

\section{EXPLORA SCIENCE CENTER AND CHILDREN'S MUSEUM, AGES: 8-14}

The Explora Young Minds reviewers are a group of science enthusiasts working with museum educators and mentors from the University of New Mexico. We enjoy learning about the brain through the articles. We also enjoy asking questions and making suggestions to help the scientists make their work more understandable for everyone! We were helped by our Science Mentor, Crina Floruta, who is a M.D./Ph.D. candidate working in a neuroscience lab and who is hoping to pursue a Neurosurgical residency in the future. She loves Albuquerque, hiking, reading, and talking about the brain with people.

\section{AUTHORS}

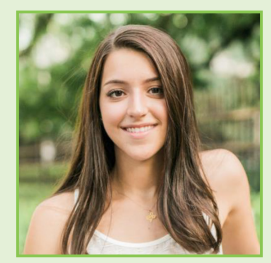

\section{STEFANIA A. CIUREA}

Stefania Ciurea is an undergraduate student at Vanderbilt University in Nashville, Tennessee. She is currently pursuing a major in Biological Sciences and minors in Spanish and Chemistry. After graduating, Stefania hopes to attend medical school 

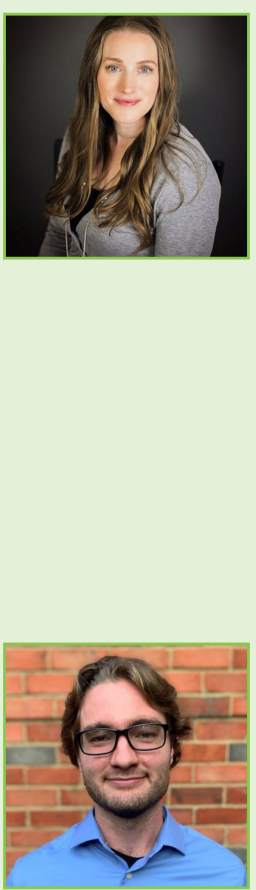

and become a doctor. Outside of school, she enjoys spending time with her two cats, drawing, playing guitar, and watching basketball.

\section{ASHLEIGH M. MAXCEY}

Ashleigh Maxcey is a Senior Lecturer and Research Assistant Professor in the Psychology Department at Vanderbilt University in Nashville, Tennessee. She teaches classes on General Psychology, Cognitive Psychology, Experimental Psychology, and Positive Psychology. Dr. Maxcey has taught thousands of students since getting her Ph.D. and she has three kids of her own, so she is really interested in why people choke under pressure, because she wants to help her students and her children succeed. Part of being a good student is juggling remembering and forgetting, which is what Dr. Maxcey studies in her laboratory at Vanderbilt. Dr. Maxcey loves traveling to cities in the U.S. and internationally to present her research. Outside of work Dr. Maxcey loves to cheer on the Vanderbilt Women's Basketball team and spend time with her family, three cats, and dog. *ammaxcey@gmail.com

\section{PHILLIP M. NEWMAN}

Phillip Newman is a Ph.D. student in the Psychology Department at Vanderbilt University in Nashville, Tennessee. Using behavioral experiments and computational modeling, Phillip's research focuses on the cognitive mechanisms underlying spatial memory and navigation. In his spare time, Phillip enjoys playing guitar, reading, and exploring cinema and music. 